\title{
HVMANITAS
}

\section{El exemplum como figura retórica en el Renacimiento}

\section{Autor(es): $\quad$ Harto Trujillo, Maria Luisa}

Publicado por: Faculdade de Letras da Universidade de Coimbra, Instituto de Estudos

URL

persistente: URI:http://hdl.handle.net/10316.2/23165

DOI: $\quad$ DOI:http://dx.doi.org/10.14195/2183-1718_63_28

Accessed : $\quad$ 26-Apr-2023 11:23:16

A navegação consulta e descarregamento dos títulos inseridos nas Bibliotecas Digitais UC Digitalis, UC Pombalina e UC Impactum, pressupõem a aceitação plena e sem reservas dos Termos e Condições de Uso destas Bibliotecas Digitais, disponíveis em https://digitalis.uc.pt/pt-pt/termos.

Conforme exposto nos referidos Termos e Condições de Uso, o descarregamento de títulos de acesso restrito requer uma licença válida de autorização devendo o utilizador aceder ao(s) documento(s) a partir de um endereço de IP da instituição detentora da supramencionada licença.

Ao utilizador é apenas permitido o descarregamento para uso pessoal, pelo que o emprego do(s) título(s) descarregado(s) para outro fim, designadamente comercial, carece de autorização do respetivo autor ou editor da obra.

Na medida em que todas as obras da UC Digitalis se encontram protegidas pelo Código do Direito de Autor e Direitos Conexos e demais legislação aplicável, toda a cópia, parcial ou total, deste documento, nos casos em que é legalmente admitida, deverá conter ou fazer-se acompanhar por este aviso. 
humanitas

Vol. LXIII

2011 


\title{
EL EXEMPLUM COMO FIGURA RETÓRICA EN EL RENACIMIENTO
}

\author{
Ma Luisa Harto Trujillo \\ Universidad de Extremadura
}

\begin{abstract}
Resumen
El exemplum era apropiado para delectare, docere y mouere en discursos, en la educación o en géneros como la historiografía. Analizamos, pues, la definición y características del exemplum según distintas retóricas desde la antigüedad al Renacimiento.
\end{abstract}

Palabras clave: exemplum, retórica, historiografía.

\begin{abstract}
The exemplum was indicated to delectare, docere and mouere in speeches, education or genres like Historiography. Then, we analyze its definition and characteristics according to some rhetorics from Antiquity to Renaissance.

Key words: exemplum, rhetoric, historiography.

\section{1.- Introducción ${ }^{1}$}

En el mundo clásico se tenía muy clara la importancia del exemplum como un recurso retórico, que permitía al orador delectare, docere y mouere, convirtiéndose pronto en un recurso fundamental en la educación

${ }^{1}$ Este trabajo se enmarca en el proyecto de investigación: "El exemplum en la retórica clásica, Plutarco y Valerio Máximo: su proyección en la historiografía cristiana y la historiografía hispanolusa en lengua latina de los siglos XV y XVI", financiado por la DGICYT (FFI2008-00939).
\end{abstract}


de los jóvenes, en todo tipo de discursos, y en géneros literarios como la historiografía, en la que llega a constituir el eje de obras como los Hechos y Dichos Memorables de Valerio Máximo.

Con el paso del tiempo, cambiaron las fuentes, los tipos, los personajes, los receptores y la finalidad de los exempla, que en la E.M. tenían un carácter oral, se usaban en sermones y tenían un claro sentido religioso. Sin embargo, en el Renacimiento, gracias a la imprenta, a la recuperación del pasado clásico y a la aparición de nuevas realidades políticas y culturales, renacen exempla basados en personajes bíblicos, clásicos, e incluso contemporáneos, que ejemplifican virtudes y glorias del pasado, encarnadas ahora fundamentalmente en los príncipes de las distintas monarquías reinantes.

De ahí la importancia de los exempla en el Renacimiento, pues ofrecen un caldo de cultivo riquísimo con el que deleitar, pero con el que ofrecer también una lección moral, viva y evidente (eso es lo que caracteriza al exemplum) de virtudes y vicios.

Queremos centrarnos pues, brevemente, en la consideración del exemplum como figura retórica en el Renacimento, como punto de partida para el estudio posterior de su utilización en la historiografía y en la difusión de un modelo de virtudes y vicios.

\section{El exemplum en la Retórica Clásica}

Ya Aristóteles citaba el exemplum como una figura retórica perteneciente más al pathos que al ethos o a las písteis, y que servía al orador para persuadir. $^{2}$

También la Retórica a Alejandro incluía probabilidad y ejemplo entre los tipos de pruebas: "Los ejemplos consisten en hechos que han sucedido de manera semejante o contraria a aquellos que nosotros estamos exponiendo. Cuando lo que dices no sea de por sí digno de crédito y quieras hacer que parezca evidente, si no puedes conseguir la credibilidad por medio de lo probable, has de usar los ejemplos para que los oyentes, al

2 "Por una parte el ejemplo (parádeigma) es una inducción; por otra parte, el entimema es un silogismo... Llamo, pues, entimema al silogismo retórico y ejemplo a la inducción (epagogé) retórica. Y, ciertamente, en orden a demostrar, todos proporcionan pruebas por persuasión aduciendo ejemplos o entimemas" Rhet.1356b 2, Racionero ed. (1990): 180. 
tener noticia de otro hecho que ha sucedido de la misma manera que el que tú expones, presten mayor crédito a lo que dices". 3

Entre los autores latinos, tanto la Rhetorica ad Herennium, como Cicerón o Quintiliano nos han ofrecido su visión del exemplum:

Exemplum est alicuius facti aut dicti praeteriti cum certi auctoris nomine propositio (Heren. 4.49.62).

Exemplum est quod rem auctoritate aut casu alicuius hominis aut negotii confirmat aut infirmat (Cic. Inv. 1.49.6).

Quod proprie uocamus exemplum, id est rei gestae aut ut gestae utilis ad persuadendum id quod intenderis commemoratio (Quintil. Inst. 5.11.6)

Rasgos esenciales, pues, del exemplum como figura retórica en la Antigüedad son:

- Su contenido: Acciones o palabras de un protagonista destacado (auctoritas). ${ }^{4}$

- Su finalidad: embellecer el discurso, enseñar y persuadir.

Commemoratio autem antiquitatis exemplorumque prolatio summa cum delectatione et auctoritatem orationi adfert et fidem (Cic. Orat. 120.16).

Id sumitur iisdem de causis, quibus similitudo. Rem ornatiorem facit, cum nullius rei nisi dignitatis causa sumitur; apertiorem, cum id quod sit obscurius, magis dilucidum reddit; probabiliorem, cum magis ueri similem facit; ante oculos ponit, cum exprimit omnia perspicue, ut res prope dicam manu temptari possit. (Heren. 4.48-49).

Por tanto, en los discursos, dice Cicerón que hay que utilizar exempla para persuadir: Utendumque exemplis, si quis testibus creditum non sit. (Part. 14.49).

Y fundamentalmente hay que utilizarlos, de manera semejante a las comparaciones, como recurso o figura de amplificación en la argumentatio:

3 Rhet. Alex.1429 a 21 sigs. Sánchez ed. (1989): 60.

${ }^{4}$ Para Quintiliano la autoridad de la persona mencionada en el exemplum aumenta su efectividad: Itaque quamuis exempla plurimum in consiliis possint, quia facillime ad consentiendum homines ducuntur experimentis, refert tamen quorum auctoritas et quibus adhibeatur (Instit, 3.8.36.2). 
Rerum amplificatio sumitur eisdem ex locis omnibus quibus illa quae dicta sunt ad fidem; maximeque definitiones ualent conglobatae et consequentium frequentatio et contrariarum et dissimilium et inter se pugnantium rerum conflictio, et causae, et ea quae sunt de causis orta, maximeque similitudines et exempla (Cic. Part. 55.1-7).

Con estas características, toda vez que el exemplum es un recurso utilizado para hacer más agradable un discurso, para enseñar y mover al receptor en un determinado sentido, comprendemos que se convierta pronto en recurso fundamental en la educación de los jóvenes romanos:

"Prácticamente, la educación moral del joven romano, como la del griego, se alimentaba por una selección de ejemplos que se ofrecían a su admiración; pero éstos estaban tomados de la historia patria, y no de la poesía heroica. Poco importaba que muchos de esos exempla fuesen legendarios: se los presentaba y se los revivía como históricos". 5

Y a partir de su utilización como elemento retórico de persuasión y de educación cívica, entendemos su importancia en la literatura, sobre todo en géneros como la historiografía, magistra vitae, pues ¿qué mejor recurso que los exempla para enseñar las grandezas del pasado y los comportamientos que permitieron obtener esa grandeza?

No olvidemos que, en realidad, la historiografía clásica, por su carácter didáctico y moralizante, por centrarse en temas bélicos y políticos, por su relación con la épica y la tragedia y por ser en gran medida autobiográfica, no es sino una colección de exempla y de relatos protagonizados por auctoritates reconocidas por todos.

"L'Histoire (romaine ou grecque) se réduit à un répertoire d'exempla, de faits et dits mémorables, utiles à confier à la memoire de l'orateur pour qu'il les ressorte à l'occasion". ${ }^{6}$

Por tanto, entendemos que en el siglo I d.C., teniendo en cuenta la degeneración de la vida y la política en Roma, y teniendo en cuenta así mismo la importancia de la retórica en la literatura latina en esta época,

\footnotetext{
${ }^{5}$ Marrou (1965): 347.

${ }^{6}$ Brémond et alii eds. (1982): 47.
} 
Valerio Máximo escribiera una obra, en la que el exemplum, antes un simple recurso retórico y educativo, se convierte en el eje central, pues su cometido es ofrecer a lectores, rétores e historiadores una selección de ejemplos, de hechos y dichos que puedan utilizar en sus escritos.

Ahora bien ¿Qué enseñan en la antigüedad los ejemplos citados en la historiografía? Pues enseñan el código moral, las virtudes y vicios que engrandecieron Roma y que hay que imitar o seguir para mantener esa grandeza:

An fortitudinem, iustitiam, fidem, continentiam, frugalitatem, contemptum doloris ac mortis melius alii docebunt quam Fabricii, Curii, Reguli, Decii, Mucii aliique innumerabiles? Quantum enim Graeci praeceptis ualent, tantum Romani, quod est maius, exemplis (Quint. Inst. 12.2.30).

Es decir, los exempla mostraban las virtudes fundamentales marcadas ya en la filosofía por Platón: prudentia, iustitia, fortitudo y temperantia o modestia. Son las que aparecen en la Rhetorica ad Herennium, que habla de modestia $(3.2 .3 ; 3.6 .10 ; 3.8 .15)$; o en Cicerón, que sustituye la modestia por la temperantia (Inv. 2.52.15).

Eran las virtudes fundamentales o "cardinales", que solían aparecer en tratados filosóficos y retóricos. Así pues, la recopilación de Valerio Máximo, la más conocida de la antigüedad, constituye un intento de ofrecer una serie ordenada de ejemplos de estas virtudes, mostrándonos la concepción moral de su época y la visión que tenían sobre determinados personajes, convirtiéndose su obra en un canto a la paz y a la tranquilidad conseguida por emperadores como Augusto y Tiberio. ${ }^{7}$

Algunos años después, Plinio el Joven, en el Panegírico de Trajano, y sobre todo al trazar la figura del noble ideal, simbolizado por Metelo, repetirá unas virtudes similares, conformando así el canon de virtudes y de ejemplos que las representan, un canon que perduraría a lo largo del Imperio.

7 “Tranquillitas, pax y quies son los tres soportes sobre los que Valerio Máximo sustenta el reinado de Tiberio, y los tres están presentes en todos los momentos de la obra”. López Moreda, S. (2003): 33. 


\section{3.- Cristianismo y Edad Media}

A medida que el Imperio fue cristianizándose, su cultura, pensamiento, literatura y recursos como el exemplum se cristianizaron también. Así, la presencia de Valerio es evidente en las Instituciones Divinas de Lactancio o en Tertuliano, que habría adaptado al cristianismo exempla paganos de la Antigüedad. ${ }^{8}$ Y si Valerio distingue en su obra entre ejemplos romanos y extranjeros, en Tertuliano se han distinguido exempla paganos y bíblicos. De este modo, virtudes como la paciencia, la bondad... ya no estarían ejemplificadas por auctoritates paganas del pasado clásico, sino por Abraham o Job.

Pero lo cierto es que los cristianos vieron también en el exemplum un medio muy eficaz para persuadir, una homilía viva, que ofrece el testimonio de mártires y santos. Como reconoce el propio San Ambrosio en el De Virginibus:

"Sed quoniam nos infirmi ad monendum sumus, et impares ad docendum (debet enim is qui docet supra eum qui docetur excellere), ne uel susceptum deseruisse munus, uel nobis arrogasse amplius uideremur, exemplis potius quam praeceptis putauimus imbuendam licet amplius proficiatur exemplo" (PL, t.16, p.207).

"Sit ratio efficax ad suadendum, validiora tamen sunt exempla quam uerba" Papa León el Grande (PL t.54, p.438).

"Plus enim plerumque exempla quam ratiocinationis uerba compungant... ad amorem Dei et proximi plerumque corda audientium plus exempla quam uerba excitant". Papa Gregorio el Grande, (PL, t.76, p.1014, 1290-1300).

Sería Gregorio Magno quien habría sentado las bases de la utilización de este recurso como medio esencial para la predicación, hasta el punto de que ha sido considerado como "padre del exemplum medieval".

En la Edad Media cambia, pues, el marco (que ahora son homilías orales), cambia la fuente (bíblicas o inventadas), la finalidad (religiosa), pero se mantiene la esencia del exemplum como recurso retórico y estético utilizado para la persuasión. El exemplum medieval se basa en santos,

\footnotetext{
${ }^{8}$ Brémond et alii eds. (1982): 48.

${ }^{9}$ Brémond et alii eds. (1982): 50.
} 
mártires, o en historias y anécdotas de carácter moral y religioso, que entretenían y movían al auditorio. No importan tanto la auctoritas o la ratio de los personajes como la fuente (la Biblia) o el narrador, a quien se considera un elegido divino. Importa también el relato en sí (que debe captar la atención de un público poco culto) y la enseñanza moral. Desde luego, el fin moralizante es la razón de ser del exemplum medieval, que utilizará en mayor medida lo cotidiano y trivial, lo folklórico y maravilloso, considerado un buen método para entretener y convencer al auditorio.

Curiosamente, al igual que sucedió en la antigüedad, a partir de los siglos XIII y XIV, la importancia de los exempla hará que comiencen a difundirse de nuevo en repertorios en los que el autor será sobre todo un compilador. Una vez más, el éxito del exemplum le lleva a dejar de ser un recurso para constituir el centro de unas recopilaciones. ${ }^{10}$

\section{4.- Renacimiento}

En los siglos XV y XVI asistimos a un nuevo cambio de orientación. Renace la importancia de los autores clásicos como fuente, unidos también a la Biblia; el auditorio de los exempla no serán sólo feligreses, sino especialmente lectores o jóvenes en las aulas, y la finalidad no será religiosa, sino de nuevo el entretenimiento y la propagación de personajes y virtudes del pasado, que servirán muy bien para crear un modelo de conducta en personajes destacados como los reyes de las nuevas monarquías.

El exemplum aparece nuevamente en retóricas y en la obra de humanistas que aconsejan su utilización, como ya hicieron Cicerón o Quintiliano, para delectare, docere y movere, pues encierra cualidades como brevedad, claridad y verosimilitud, que son muy apreciadas en cualquier texto renacentista.

Por eso seguimos encontrando repertorios de exempla, valorados por humanistas como Petrarca, que los toma como fuente para su De viris

${ }^{10}$ Del XIII al XIV, podemos hablar de más de 46 repertorios de exempla (Cf. Brémond et alii eds. Ibidem: 58). Serían colecciones incompletas, anónimas, sin título y que, en gran parte, retoman los mismos exempla, si bien puede variar el orden (alfabético, por temas...). Entre ellas podemos mencionar el Dialogus Miraculorum o los Libri octo miraculorum del cisterciense Cesareo de Heisterbach; la anónima Tabula exemplorum secundum ordinem alphabeti, que contiene unos 300 ejemplos; o el Alphabetum Narrationum de Arnold de Lieja, que usa el criterio alfabético pero también el temático. 
illustribus, ${ }^{11}$ insistiendo en que en su obra no hay teorías ni sabidurías, sino ejemplos prácticos, que no se basa en nada científico, sino en verdades históricas, auténticas, consideradas un método esencial de persuasión, al apoyarse en autoridades reales del pasado.

Colecciones como la de Valerio se transmiten manuscritas o en tempranas ediciones incunables, junto a nuevos repertorios de adagios, apotegmas, citas... que, junto a la realidad, serán las fuentes de los que tomarán los humanistas argumentos para la inventio:

Nec praetermittenda uidentur ab historiis petita exempla, quae in exercitatione quotidiana nostrorum discipulorum frequentissime a nobis usurpabuntur. ${ }^{12}$

Junto a las ediciones, se editan también comentarios de Valerio y su obra se convierte en lectura obligada en universidades de la península, desplazando a autores como Terencio y Ovidio en Salamanca. Humanistas como Juan de Valdés o Vives incluyen a Valerio entre los historiadores que hay que leer, junto a Livio, César, Quinto Curcio y otros. ${ }^{13}$

También Erasmo muestra pronto su interés por este recurso para conseguir belleza y eficacia dentro de las técnicas relacionadas con la abundancia oratoria. Así, en el De copia trata modos de dilatación ejemplares, distinguiendo procedimientos como el elogio del autor de la narración, del protagonista o de la propia materia del relato, esbozando, como indica Araguiés, "la primera teoría específica sobre el desarrollo narrativo del género ejemplar". ${ }^{14}$

En concreto, en el capítulo dedicado por Erasmo al exemplum en el De duplici copia, repite casi literalmente la definición de Quintiliano (est autem rei gestae aut perinde ut gestae utilis ad persuadendum commemoratio), ${ }^{15}$ tras lo cual indica que un ejemplo puede expresarse

${ }^{11}$ Incluso Giovanni da Prato, en su Paradiso degli Alberti, critica el número de libros de Tito Livio y afirma, sin embargo, que Valerio Máximo es demasiado breve. Cf. S. López, (2003): 61.

${ }^{12} \mathrm{~V}$. blas garcía (1581): 18 .

${ }^{13}$ López, S. (2003): 66, que cita al Diálogo de la lengua de Juan de Valdés; Vives, De disciplinis III ,6, De ratione dicendi, en Riber, L (1948), Tomo II: 784.

${ }^{14}$ Aragüés, J. (1997): 728.

${ }^{15}$ Erasmo (1546): 237. Esta definición de Quintiliano es la elegida también 
como una simple mención, o bien desarrollado mediante comparaciones centradas en la similitud, disimilitud, en lo contrario o en el tamaño mayor o menor, lo cual permitirá al orador extender el ejemplo copiosissime, si va comparando y explicando cada una de las partes.

Y ¿qué mejor manera de explicar esto que mediante un ejemplo, tomado en este caso de Cicerón?:

Illi libertatem ciuium Romanorum imminutam non tulerunt, uos uitam neglectam negligetis? Ius legationis uerbo uiolatu, illi persecuti sunt, uos legatum omni supplicio interfectum relinquetis? Videte ne ut illis pulcherrimum fuit, tantam uobis imperii gloriam relinquere: sic uobis turpissimum sit, id quod accepistis, tueri et conseruare non posse. ${ }^{16}$

También Palmireno en su retórica indica cómo alargar los exempla:

Augentur ergo laude rei, auctoris, gentis unde sumuntur... Augentur etiam exempla, si fusius aut latius explicentur cum exaggerationibus, aut amplificationibus. ${ }^{17}$

Y así pueden ir alargándose los ejemplos con el añadido de frases sentenciosas y con la comparación de todas las circunstancias que diferencian o asemejan el ejemplo propuesto a la realidad, añadiendo también Erasmo que, en los casos reales, encuentra el orador más circunstancias que comparar, lo cual le lleva a oponer, también mediante un ejemplo, la actitud de una madre pagana que había perdido a todos sus hijos y lo había soportado con resignación, a la actitud de un padre cristiano, incapaz de soportar la pérdida de un solo hijo.

por Nebrija en su Compendiosa Coaptatio, (1529) Alcalá, en el capitítulo XVII dedicaco a la ratiocinatio. Además, en esta misma obra, (capít. XXIII, De genere deliberatiuo) Nebrija toma también de Quintiliano su opinión acerca de la importancia de la persona citada en el ejemplo: Quamuis exempla plurimum in conciliis possint, quia facillime homines ad consentiendum exemplis ducuntur, refert tamen quorum autoritas et quibus adhibeatur (Instit. III,8,36,2).

${ }^{16}$ Erasmo, ibidem: 237. El ejemplo de Cicerón aparece en De imperio Cn. Pompei 11. Tanto la doctrina erasmiana como el ejemplo concreto de Cicerón aparecen también en el libro III del De arte dicendi de Palmireno, (1578): 30.

${ }^{17}$ Palmireno (1578): II, 28. 
La doctrina erasmiana sobre la utilización y la manera de expresar y amplificar los ejemplos fue retomada por varios humanistas, ya en retóricas propiamente dichas como hacen Palmireno o fray Luis de Granada, ya en textos similares al De Copia, como el Tratado en que consisten la brevedad y la abundancia de Miguel de Salinas.

Por otra parte, como recurso retórico de amplificación, el exemplum sigue siendo, como en la Antigüedad, un ejercicio de preparación o progymnasma muy útil para el alumno, como afirman Pedro Juan Núñez o el padre Escardó: ${ }^{18}$

Narratiuncularum usus latissime patet in confirmatione, cum sententiam nostram cum exemplis confirmamus (Nuñez (1578): f.9 r)

"Suelen los aficionados a la elocuencia, antes de llegar a lo más difícil de toda ella, que es hazer oraciones con artificio rhetorico, ejercitarse primero en los progymnasmas, que llamó Quintiliano opera minora... Una destas obras se llama narraciúncula, y el que la supiese dilatar dilatará también un ejemplo, por breve que sea... Y no dexarán de ser de mucho provecho, assí para los estudiantes de Rhetorica, como también para los Predicadores, que en varias ocasiones cuentan ejemplos, que son historias verdaderas, y se podrán servir de las mismas reglas que daremos para dilatar las que son fingidas" (J. B. Escardó (1648): ff.99r-102 v).

$\mathrm{Y}$, por supuesto, en las retóricas, el exemplum sigue siendo mencionado como figura de pensamiento, que funciona por extensión semántica, y que suele aparecer en las argumentaciones con un uso semejante al del símil.

En este sentido se expresa L. López Grigera, para quien: "En el ámbito de la argumentación entraba la riquísima gama de ejemplos, apotegmas, cuentecillos, que servían para entretener y para mover". ${ }^{19}$

Esto lleva a que todos estos recursos y figuras se confundan y no sea siempre fácil establecer la diferencia entre un exemplum, una comparación, una parábola, una inducción lógica... Así lo reconocen entre otros Palmireno, Pedro Juan Núñez, Alfonso García Matamoros o Arias Montano:

Parabolam ab exemplo permulti sic distinguunt, ut exemplum sit certae rei gestae, parabola et similitudo ab his quae fiunt, aut quae natura, casuue rebus adiuncta sunt, ut Attilius ad hostes reuersus exemplum est seruandae

${ }^{18}$ En Aragüés (1997): 723.

${ }^{19}$ López Grigera (1994): 23. Ibid: 19, 20 y 24. 
fidei, at nauis pro uentorum ratione uelum tollens, aut contrahens parabola est, quae docet sapientem tempori cedere. ${ }^{20}$

Difficilius autem est argumentum a pari distinguere ab exemplo et a similitudine, negari siquidem non potest, quin multa exempla paria sint et multa item similia. Dicam igitur exempla ex factis et dictis certarum personarum duci, paria uero non ex certis aut singulis personis, sed ex communibus atque etiam ex aliis generibus rerum peti. ${ }^{21}$

Porro exempli nomen latissime patet, nam quanquam appellatione propria id demum exemplum dicatur, quum res gesta, ac perinde ut gesta exhortandi causa proponitur, tamen illustrium uirorum grauiter dicta, philosophorum paradoxa, poetarum figmenta, authorum nobilium sententiae, paroemiae uulgo receptae, allegoriae, parabolae et ut sacra etiam completamur, figurae et oracula breuiter quidquid similitudinibus est affine, id exempli uim habet et a Fabio huic generi subiicitur. ${ }^{22}$

Sunt qui exempla uocent. Sed nos exempla uocamus, quando a personis personarum quoque gestis argumentandi uires inducimus: at cum ab reliquis rerum naturis pondera, uimque et argumenta trahis, simplex inductio tunc sit. $^{23}$

Lo que caracterizaría, pues, al ejemplo frente a los otros recursos es que se basa en dichos y hechos de personas ciertas y reconocidas, si bien son los propios humanistas los que no siempre utilizan este criterio restrictivo y quienes confunden y equiparan con frecuencia en su obra similitudines y exempla.

Ciertamente, esta confusión se daba ya en la antigüedad o incluso en la actualidad, y se debe sobre todo a dos factores relacionados con el contenido y la finalidad. Así, en cuanto al contenido, uno y otro son recursos basados en la utilización de referentes que se comparan o se relacionan con personas o situaciones de la realidad y, en cuanto a la finalidad, coinciden

${ }^{20}$ Palmireno (1578): III, 30-31.

${ }^{21}$ Nuñez (1585): 239-40. En un capítulo de título muy significativo: De ratione dilatandi argumenta.

${ }^{22}$ García Matamoros (1570): p.129.

${ }^{23}$ Arias Montano (1569): 74. 
en ser recursos retóricos utilizados para deleitar, enseñar y mover así mejor al receptor.

Es la finalidad que siempre se ha destacado como propia del exemplum en las retóricas. Así lo encontramos, en el Renacimiento, en varias obras de este tipo:

Prosunt hic uehementer exempla ab historicis petita. Nam futura a praeteritis certius colliguntur, et alienae fortunae successu animi audientium uel demittuntur, uel eriguntur..$^{24}$

Adhibentur exempla ad aliquid probandum, ad laudes, consolationem, uituperationem, et ad animos permouendos. ${ }^{25}$

En este pasaje lo relaciona Blas García con el docere y mouere, aunque, un poco más adelante, lo relacionará también con el delectare, al citar los recursos que debe utilizar un orador en la narratio para captar la atención del oyente:

Cum sint non raro audientium animi faceta et hilari oratione leniendi, idcirco laetum orator, plausibilemque locum exquirit, et oportuna digressione auditores reficit et recreat. Hac uti licebit, ut augeamus factum, aut euertamus quaestionem, seu occupemus argumenta; aut animos auditorium a consideratione criminis, attentioneque nimia auertamus. Id fit loco communi, querela, laude hominum, et aliarum rerum; aut conuitio, descriptione, fabula, historia, exemplo, similitudine, facetiis, et acuto aliquo commento, quale est Demosthenis, de Asini umbra. ${ }^{26}$

También Vives habla del deleite y utilidad de los exempla: "El espíritu tiene sus placeres. Deléitannos las narraciones festivas, los dichos agudos y cuerdos; las réplicas saladas y picantes. Aun a las personas de gravedad les complacen los aforismos sabios y bien acuñados; a los varones probos, los ejemplos de virtud". ${ }^{27}$

\footnotetext{
${ }^{24}$ Palmireno (1578): III, 70.

${ }^{25}$ Palmireno (1578): III, 28; Blas García (1581): 27.

${ }^{26}$ Blas García (1581): 16.

${ }^{27}$ Vives, De ratione dicendi, II, en L. Riber (1948): 753.
} 
Pero, dejando a un lado el deleite, los humanistas no olvidan nunca la función probatoria del ejemplo, lo cual les lleva a que, a la hora de establecer el orden de los argumentos que debe utilizar el orador, el ejemplo aparezca por delante de aquellos centrados simplemente en la amplificación u ostentación:

Antecedent ea quae habent uim probandi, sequantur uero ea quae ad amplificandum magis sunt accomodata et ad ostentationem popularem aptiora... Hinc in argumentationis ordine argumenta et exempla primum collocantur, deinde enthymemata, epenthymemata atque ficta argumenta. ${ }^{28}$

Además del orden o de la finalidad de su uso, en las retóricas se apunta también la fuente de la que tomar exempla. Así lo hace Blas García, para quien: nec praetermittenda uidentur ab historiis petita exempla, quae in exercitatione quotidiana nostrorum discipulorum frequentissime a nobis usurpabuntur (29, p.18).

Ahora bien, los humanistas utilizan también como fuentes para sus ejemplos además de a los historiadores, la realidad, a los poetas, fabulistas... Así lo indica Pedro Juan Núñez:

Exempla, quae suppetent ex poetis, historicis et fabularum scriptoribus. ${ }^{29}$

Se observa, no obstante, que los ejemplos mitológicos y literarios se usan en géneros poéticos, en los que domina la función del deleite sobre la enseñanza. Mientras que historiadores, maestros y filósofos prefieren ejemplos tomados de la realidad o de la historiografía.

Por otra parte, como ya apuntamos a propósito de Erasmo y el $D e$ copia, los exempla aparecen en las obras retóricas muy relacionados con figuras como la amplificatio o la comparatio. ${ }^{30}$

De hecho el Brocense (El arte de hablar:.96) considera que exempla y similitudines se utilizan en la amplificatio, esa parte que, conmoviendo los ánimos, consigue credibilidad, y que se basa en la elección ya de palabras (verborum), ya de temas (rerum), unos temas en los que incluye tópicos, definiciones... semejanzas y ejemplos. Y un poco más adelante, insiste

\footnotetext{
${ }^{28}$ Nuñez, (1585): 256.

${ }^{29}$ Nuñez (1585): 21.

${ }^{30}$ Cfr. Blas García (1581): 18.
} 
también el Brocense en el carácter argumentativo y persuasivo del exemplum, pues dentro del capítulo sobre la argumentatio, cita recursos como complexio, enumeratio, simplex conclusio, subiectio, antitheton, inductio, uiolatio, enthymema, sorites. Pues bien, dentro de la inductio, dice:

Fit cum plura exempla pluresue similitudines ad unum effectum congeruntur.

A partir de esta utilización del exemplum como recurso retórico tomado de la realidad o bien de los propios historiadores clásicos, comprendemos que esta figura siga siendo fundamental en el Renacimiento, especialmente en géneros como la historiografía, a la que sirve para ofrecer un código moral de virtudes y vicios, tal como había ocurrido ya en el mundo clásico:

Decem sunt omnino argumentorum genera, quibus utitur orator: sed nullo perinde argumenti genere ad uirtutem incitamur, ut eorum quos admiramur exemplis, maximeque illustribus, peruetustis ac domesticis. ${ }^{31}$

Vivi consilio, prudentia fortitudine, iustitia et reliquis animi bonis Reipublicae prosunt maxime; secundis rebus laetitiam augent; aduersis remedia adhibent salutaria et ueluti Dii quidam inmortales, magna, et plurima uel in suos ciues uel in patriam, uel in omne hominum genus beneficia conferunt; mortui (quanquam quomodo mori possunt illi, quos ante obitum praeclarissimae uirtutes reddiderunt inmortales) exemplo, et memoria recte factorum ad honestas actiones, exercendasque dignas uiro uirtutes accendunt. ${ }^{32}$

Los ejemplos del pasado siguen siendo, pues, el mejor recurso para enseñar las virtudes esenciales que, nuevamente, siguen siendo las virtudes de las que hablaban los clásicos.

Ahora bien, este exemplum renacentista no siempre conservaba la veracidad de lo narrado. Es el caso de los exempla utilizados por fray Antonio de Guevara, quien para muchos críticos "se inventa los exempla en un número casi total de los casos". ${ }^{33}$

${ }^{31}$ García Matamoros (1570): 129. La cita aparece en un capítulo muy significativo: De exemplo et quo modo tractandum sit.

${ }^{32}$ Blas García (1581): 9.

${ }_{33}$ M. Guillén distingue tres tipos de exempla en este autor: inventados completamente; inventados pero con mezcla de elementos reales, y los que tienen 
Esta falsedad de los exempla historiográficos será reprochada por humanistas como Erasmo o Vives, que plantearon además dudas no sólo hacia la veracidad, sino también hacia el comportamiento de los héroes, dichos y hechos elogiados por los historiadores de la antigüedad. No en vano, si bien Erasmo era un gran lector de historia, si la biografía le interesa como pedagogo, porque ofrece una relación detallada de datos útiles para la formación del príncipe (homines non nascuntur, sed finguntur), si en la Institutio Principis muestra su aprecio por el estilo y la lectura de Salustio y de Tito Livio, lo cierto es que Erasmo criticaba que la historiografía se centrara y elogiara el comportamiento de "héroes" en guerras civiles y extranjeras.

Y lo mismo plantea Vives, para quien: "Lo primero que en la Historia debe retenerse es la cronología o razón de los tiempos; luego, los hechos y los dichos que puedan tener ejemplaridad, así para imitar lo bueno como para evitar lo malo. No se ha de poner cuidado excesivo en seguir las guerras y las batallas, que solamente instruyen para el daño y enseñan los procedimientos con que poder lesionarnos mutuamente...

Mejor se hará dando preferencia a los temas de la paz: rememorar todo cuanto se hizo ilustre y sabiamente en el terreno de la virtud y cuanto se hizo de atroz y feo en el terreno de la maldad; el buen suceso de las cosas bien hechas, las tristes consecuencias de las malas obras.

Luego vendrán las sentencias y las respuestas agudas de los hombres dotados de ingenio, enriquecidos de experiencia, especialmente aquellas que con voz griega se denominan apotegmas. A continuación, los consejos y determinaciones; por qué se concertó tal empresa; cómo se llevó a cabo; las palabras de quienes descollaron sobre los otros en probidad, sabiduría y conocimientos en las buenas letras, como son los filósofos entre los cuales los sobresalientes son los santos de nuestra religión, por manera que no solamente estemos informados de los hechos que ocasionaron las pasiones desapoderadas de los hombres, sino de aquellos otros inspirados y alentados por la fuerza de la mente y del juicio". ${ }^{34}$

Para Vives o Erasmo, no había que confiar en un género literario en el que se mezclaban la verdad, prodigios, presagios, hazañas guerreras, digresiones exóticas, discursos ficticios y topoi. Es decir, aprobaban la

una fuente concreta, más verídicos, que suelen ser bíblicos. (1998): 422 y 428.

${ }^{34}$ Vives, De disciplinis, V,1, en L.Riber ed. (1948): 650. 
forma de la historiografía romana y su utilización a la hora de educar a los jóvenes, pero no tanto el fondo, pues la primera regla de la historia es la fides, que no siempre se respeta en los exempla ya desde la antigüedad:

"Selon lui (Erasmo), le devoir d'enseigner la morale à travers des exempla peut amener l'historien à déformer la vérité historique; pourtant, seule cette vérité grâce à sa force, à son authenticité, rendra l'histoire utile dans ce domaine, car c'est dans les récits historiques vrais que le moraliste puisera les détais susceptibles d'illustrer efficacement ses préceptes". ${ }^{35}$

Por tanto, los ejemplos deben ser ciertos y, además, apropiados al tema de que se trate, pues como dice Vives, citando a Marcial, no podemos tratar de un asunto vulgar como unas cabras, poniendo ejemplos de Cannas y Aníbal, pues eso sería pasar del zueco al coturno o suscitar tempestades en un vaso de agua. ${ }^{36}$

Varias son, pues, las razones por las que, en opinión de J. Hirstein (ibid. p.73), Erasmo desconfiaba de los exempla en la educación:

- En primer lugar, porque los ejemplos ofrecidos por la historia antigua no eran sino de guerreros ilustres, que sólo podían inspirar al príncipe un espíritu bélico. ${ }^{37}$

- Porque los historiadores los inventaban, lo cual les quitaba todo valor pedagógico (cf. Vida de San Jerónimo, en Erasmi Opuscula..., W.K. Ferguson ed. (1933), La Haya:135-6; 47-48).

- Porque, frente a ellos, los apotegmata, dan una imagen más fiel y vívida del personaje (cf. Pr. Apoph: 55-63).

Así pues, Erasmo considera que los exempla son un recurso retórico fundamental para desarrollar un discurso, persuadir y mover al receptor. Apunta, además, cómo presentar los exempla para que tengan más eficacia oratoria (desarrollándolos con comparaciones, frases sentenciosas...). Y, sin embargo, desconfía de su utilización en la educación o en la historiogra-

${ }^{35}$ J. Hirstein (1990): 73

${ }^{36}$ VIVES, De ratione, en L.Riber (1948): 764.

${ }^{37}$ Así lo expone en el prefacio a Q. Curcio (cf. Allen III, Ep.704, 28-30 del 4-11-1517), donde critica a historiadores griegos, o en la Institutio (Herding ed., (1974) 180-2, líneas 452-62; 477-89 y 494-8; o J.D. Tracy (1978), The politics of Erasmus..., Toronto: 62. 
fía, tanto porque pone en duda la veracidad de los exempla utilizados por los historiadores de la Antigüedad o del Renacimiento, como porque pone en duda también los valores que se defienden en esos exempla (normalmente valores guerreros).

A pesar de las reservas de Erasmo, hemos visto cómo, al igual que en la Antigüedad, los exempla constituyen en el Renacimiento un recurso retórico fundamental para deleitar, enseñar y mover tanto en todo tipo de discursos, como en la educación de los jóvenes y en géneros literarios como la historiografía. En este género, los ejemplos aportan un cuadro vivo de virtudes y vicios, es decir de aquellos comportamientos que los humanistas quieren extender entre el pueblo, educando y conformando a sus príncipes, que son el modelo a imitar por todos, a imagen y semejanza, no de héroes guerreros, sino de los héroes virtuosos y prudentes del pasado.

\section{Bibliografía}

ARAgüÉs, J. (1997), “Ars dilatandi exempla. Teorías sobre la amplificación narrativa del exemplum en los siglos XVI y XVII", en J. Ma Maestre et alii eds., Humanismo y Pervivencia del Mundo Clásico, Cádiz: 721-733.

Arias Montano, B (1569), Rhetoricorum libri III, Amberes.

Brémond, C. et alii eds. (1982) L'exemplum, Turnhout, Brepols.

Erasmo (1546), De duplici copia, Lyon.

García, BLAS, (1581) Brevis epitome, Valencia.

García Matamoros, A (1570), De methodo concionandi, Liber unus, Alcalá.

Guillén, M. (1998), "Los exempla bíblicos en la prosa artística de fray Antonio de Guevara", Actas Congreso Internacional sobre Humanismo y Renacimiento, M. Pérez (ed.), León.

J. Hirstein (1990), "Erasme, l'Histoire Auguste et l'histoire", en Actes du colloque internacional Érasme, J. Chomarat, A. Godin y J.C. Margolin (eds.) Ginebra.

López Grigera, L. (1994), La retórica en la España del Siglo de Oro, Salamanca.

López Moreda, S., Harto, Mª L., Villalba, J, trads. (2003) Valerio Máximo, Hechos y dichos memorables, Madrid, Gredos. 
Marrou, H. I. (1965), Historia de la educación en la Antigüedad, Buenos Aires.

Nebrija, (1529), Compendiosa Coaptatio, Alcalá.

NuÑEz, Pedro Juan (1578) Institutiones Rhetoricae..., Barcelona.

(1585) Institutionum rhetoricarum libri $V$, Barcelona.

Palmireno (1578) De arte dicendi, Valencia.

Racionero, Q. ed. (1990), Aristóteles, Retórica, Madrid, Gredos.

Riber, L, trad. (1948) Vives, Obras completas, Madrid, Aguilar.

SÁncheZ ed. (1989), Retórica a Alejandro, Salamanca.

Sánchez De Las Brozas, F, El arte de hablar (1556), ed. y trad. de L. Merino, Alcañiz-Madrid, 2007. 